\title{
Polymorphisms in BDNF (Val66Met) and 5-HTTLPR, morning cortisol and subsequent depression in at-risk adolescents ${ }^{\dagger}$
}

\author{
Ian M. Goodyer, Tim Croudace, Frank Dudbridge, Maria Ban and Joe Herbert
}

\section{Background}

There is increasing evidence for genetic effects on the hypothalamic-pituitary axis system. More than one gene is likely to moderate corticoid-mediated activity.

\begin{abstract}
Aims
To investigate whether the brain-derived neurotrophic factor (BDNF) polymorphism (rs6265, val66Met) is associated with morning waking salivary cortisol and moderates the corticoid-mediated risk for subsequent depressive episode onset independently of the known effects of 5-HTTLPR (the serotonin transporter gene promoter)
\end{abstract}

\section{Method}

High-risk adolescents $(n=401)$ were genotyped for Val66Met BDNF and 5-HTTLPR. Salivary samples were obtained on four consecutive school days within $1 \mathrm{~h}$ of waking. There were 365 (91\%) remaining participants reassessed at 12 months for episodes of psychiatric disorder in the follow-up period. Of these, 357 (89\%) had complete data for multivariate modelling.

\section{Results}

There were $41(11.2 \%)$ individuals who reported a new episode of clinical depression over the follow-up period. Increased risk for subsequent depression was found in carriers of the Val66Val genotype in BDNF with higher morning waking cortisol. This remained present when the known interaction between carriers of a short allele of 5-HTTLPR with higher morning salivary cortisol was taken into account.

\section{Conclusions}

Both BDNF and 5-HTTLPR genes show evidence of modifying the risk of a subsequent new depressive episode associated with elevated morning salivary cortisol. In adolescents morning salivary cortisol levels may constitute a biomarker for some forms of unipolar depression.

\section{Declaration of interest}

None.
Depression is a serious mental disorder that emerges during the adolescent years; $30 \%$ of such onsets run a chronic or relapsing course into adult life. ${ }^{1,2}$ There is a need to identify biological measures (biomarkers) for depression to improve the specificity of current psychosocial risk profiles, as an aid in validating early interventions and treatments as well as assessing risk for recurrence. Few biomarkers have been detected for mental disorders because of the complexity of the behavioural phenotypes and an incomplete understanding of the neurobiology of psychopathology. The limited success of genetic studies to date with modest main effects (odds ratios of 1.3 or less) ${ }^{3}$ suggests that a more successful way forward may be to detect genetically sensitive physiological markers that index aetiological processes, treatment response and/or outcomes of mental illness. ${ }^{4}$ Studies have tended to focus on single risk markers for mental illnesses yielding relatively low estimates of subsequent disorders. In this paper we take a more integrative approach as outlined in the National Institute of Mental Health's 2009 Strategic Plan (www.nimh.nih.gov) to identify a genetically sensitive physiological indicator of a mental illness. We investigate the effects of three potential risk factors, a common variant in two separate genes (BDNF (brain-derived neurotrophic factor) and 5-HTTLPR (the serotonin transporter gene promoter)) and one endocrine marker (morning cortisol level) each with known neurobiological functions, for onset of a new depressive episode. We carried out this investigation in the context of a set of other known risks that included family psychiatric history, gender and negative emotional temperament. We hypothesise that as BDNF, 5-HTTLPR and

†See pp. 341-342, this issue cortisol are known to relate to each other in neurobiologically meaningful ways ${ }^{5}$ their interrelationships will improve aetiological understanding for the subsequent onset of depression. For example a common feature of the neurotrophic and serotonergic systems is their ability to regulate the development and plasticity of neural circuits involved in mood disorders such as depression and anxiety. Brain-derived neurotrophic factor also promotes the survival and differentiation of 5-HT (5-hydroxytryptamine) neurons. Elevated morning salivary cortisol levels index an endophenotype ${ }^{4,6}$ that is associated with a modest increase in risk for depression onset independently of the very large risk associated with the antecedent level of depressive symptoms or undesirable recent life events. ${ }^{7}$ Elevated glucocorticoid levels may reduce $B D N F$ mRNA expression in the hippocampus ${ }^{8}$ and interfere with the ability of BDNF or serotonin-acting drugs to promote neurogenesis. ${ }^{9,10}$ We were therefore interested both in the effects of each polymorphism on the level of morning salivary cortisol, and in the effects of possible interactions between polymorphisms and cortisol levels on the risk of depression. Such interactions would be consistent with a moderating effect of genetic polymorphisms on the risk of depression associated with elevated cortisol levels within the normal range. ${ }^{5}$

A common genetic variant of the BDNF gene (rs6265: Val66Met) is associated with a decrease in the activity-dependent secretion of $\mathrm{BDNF}^{11}$ and processing of pro-BDNF to mature BDNF. A review of 14 published association studies (2812 cases and 10843 controls) of the Val66Met variant in the BDNF gene in adults with unipolar major depression showed very modest associations for males only. ${ }^{12}$ There is also the suggestion that the more common Val66Val ancestral form may be implicated in early ( $<20$ years) mood disorder. ${ }^{13}$ These discrepancies may 
be overcome in part by taking into account the integrative relationships between BDNF and other experiential, genetic, psychosocial or physiological indices. Such approaches have begun to be reported. For example, cross-sectional studies of well adults have suggested epistasis for the Val66Met BDNF polymorphism in protecting against deleterious effects of the short allele of 5-HTTLPR on brain volume. ${ }^{14}$ There is also evidence that gene variants in BDNF, including rs6265, moderate individual responses to rewarding and stressful events thereby influencing individual risks for affective disorders. ${ }^{15,16}$ Currently there is no consensus on the precise relationship between the variants in this BDNF polymorphism (rs6265: Val66Met) and risk for affective disorders emerging at different ages.

A second common variant, the short (' $s$ ') as opposed to the long ('l') polymorphism in 5-HTTLPR is postulated to be associated with affective disorders via interactions with the number of adverse life events to predict depression, which has been supported in a recent meta-analysis provided that the method for the retrospective collection of recent life-events experience uses comprehensive semi-structured interview methods and not brief questionnaires. ${ }^{17-19}$ Our recent prospective study ${ }^{20}$ of at-risk adolescents indicates that increased levels of morning waking salivary cortisol are associated with the onset of depression in the presence of the ' $\mathrm{s}$ ' allele of 5-HTTLPR suggesting that this variant increases sensitivity to this hormone. There is no information on whether $B D N F$ variants independently influence individual sensitivity to cortisol thereby altering the risk for subsequent depression. If either of these were the case, then it would further refine the characteristics of a biomarker for depressive disorders, an aetiologically heterogeneous group of mental illnesses. This paper reports an investigation into the effects of BDNF with morning cortisol on the subsequent onset of a new depression episode taking the effects of 5-HTTLPR and other risks into account, including premorbid depressive symptoms and the occurrence of an adverse life event, both well-known to be associated with subsequent new depressive episode onset.

\section{Method}

\section{Participants}

A sample of 401 medically well White European adolescents aged 12 to 16 years at psychosocial risk for unipolar major depression $(\mathrm{DSM}-\mathrm{IV})_{-}^{21}$ were recruited from 11 secondary schools in the Cambridgeshire region of the UK. The study was approved by the local ethics committee and written informed consent for participation from the adolescent and one parent or guardian was obtained. Participants were recontacted 12 months later and $365(91 \%)$ agreed to a mental state re-evaluation. There were no major differences $(P>0.1)$ between the retained sample and those who were not followed up in terms of demographics (age, gender), risk status, morning cortisol levels, and mean level of depressive symptoms or distribution of the BDNF and 5-HTTLPR alleles.

\section{Psychosocial risk profile}

Psychosocial risk was defined as having a parent with a psychiatric history $(216,54 \%)$, or two or more other risks consisting of: two bereavements over the young person's lifetime (192, 48\%), a negative emotional temperament $(133,33 \%)$, chronic $(>6$ months) marital disharmony or parental separation (186, 46\%), two recent undesirable life events or difficulties with family or friendships over the past 12 months $(121,30 \%)$. We made no attempt to stratify the sample by number of risks or type, but retained the risk score (number). The sample is not representative of the Cambridgeshire school population. As a condition of ethical approval those with a recent (past 2 years) history of overt maltreatment or who were on the UK child protection register were also excluded.

\section{Psychopathology measures}

At entry the adolescents completed a semi-structured psychiatric interview, the Schedule for Affective Disorders and Schizophrenia for School-Age Children - Present and Lifetime Version (K-SADS-PL). ${ }^{22}$ Those with current or recent (past 3 months) depressive disorder were excluded from the study to restrict outcomes to new depressive episodes only. Individuals with three or four depressive symptoms but who did not meet clinical criteria for unipolar depression $(n=18)$ were retained. Individuals were assessed for all disruptive behavioural and anxiety disorders and retained. Participants were reassessed at 12 months using the same measures and all episodes of DSM-IV-defined major depression and probable major depression over the follow-up period (four symptoms together with psychosocial impairment defined as a Children's Global Assessment Score of $<60)^{23}$ were established together with new and persistent episodes of anxiety and behavioural disorders. All participants were administered a 33-item self-report measure of current depressive symptoms, the Mood and Feelings Questionnaire (MFQ), ${ }^{24}$ at entry: 385 (96\%) provided useable data. This questionnaire has established criterion-related validity for use in adolescents with depression. ${ }^{25}$ The internal consistency reliability estimate in this sample was high (Cronbach $\alpha=0.96$ ) and the marginal reliability under item-response theory (IRT) exceeded 0.9. The sum score correlated $>0.95$ with IRT-based estimates.

\section{Recent life events}

At follow-up, a life-events interview was completed by the adolescents. Recent events were included for analysis if they were rated by the adolescents as having a moderate to severely undesirable impact on themselves lasting at least 2 weeks and occurred in the month immediately prior to onset as these are associated most with depression onset in young people. ${ }^{7}$ Those deemed possibly not severe, low in impairment or likely to have been brought about by illness-related behaviours were excluded $(<5 \%)$. A panel of raters $(n=4)$ checked all life-events ratings and where ratings were ambiguous a consensus rating was made. Panel raters were independent of the interviewer who collected the information on events and did not know whether the adolescent had received a diagnosis at the time of their rating. Test-retest ( 2 weeks, $n=40)$ reliability for all events $(\kappa>0.85)$ and agreement with parent report $(\kappa=0.9)$ were satisfactory. Research interviewers also showed good general agreement with each other $(90 \%)$ and with adolescents' subjective ratings of level of undesirability $(\kappa=0.8)$. This semi-structured procedure evaluating the quality and number of such events is considered a more appropriate procedure for genetically sensitive studies than using simple, self-completion checklists. ${ }^{18}$

\section{Cortisol assay}

Participants provided samples of saliva at $08.00 \mathrm{~h}$ and recorded their waking time on 4 consecutive schooldays within a week of the interview (99\% 2 days, $98 \% 3$ days, 95\% 4 days). Mean time between waking and morning salivary cortisol collection was $50 \mathrm{~min}$. Cortisol was measured by ELISA on $20 \mu \mathrm{l}$ samples of saliva without extraction (antibody Cambio UK). Intra-assay variation was $5.7 \%$; inter-assay variation was $5.6 \%$. Results are reported in $\mathrm{ng} / \mathrm{ml}$. 


\section{Genotyping}

Their DNA was harvested from a separate saliva sample (Qiagen, Crawley, UK) also collected at entry and genotyped for 5-HTTLPR and BDNF. The 5-HTTLPR region was genotyped as described elsewhere. ${ }^{20}$ The frequency of the common Val66Met (rs6265) BDNF polymorphism was determined commercially (Geneservice, Cambridge UK, www.geneservice.co.uk) using a custom-designed assay (Applied Biosystems, www.appliedbiosystems.com).

\section{Statistical analysis}

We determined whether individual differences in morning salivary cortisol levels were influenced by genetic variants in BDNF and 5-HTTLPR using mixed-effects linear regression computing the intraclass correlation using STATA version 10 for Windows. This is reported in the online Table DS1. We predicted depression onsets using a multiple logistic regression model, ${ }^{26}$ implemented in $R$ for Windows. ${ }^{27}$ The binary outcome was the onset of a DSM-IV major depressive episode at any point over the follow-up period of 1 year. Morning salivary cortisol level, MFQ score and total number of risks at study entry were entered as continuous variables. The presence or absence of one or more undesirable life event in the month prior to new episode onset was included as a categorical variable. Our model included main effects for all variables, including BDNF and 5-HTTLPR, together with twoway interactions between BDNF and cortisol and between 5-HTTLPR and cortisol. We did not include the two-way interaction between BDNF and 5-HTTLPR as we were primarily interested in their interactions with cortisol; however, we note that such an interaction, if present, would bias our estimates of the main effects of the two polymorphisms and their interactions with cortisol. We considered a possible three-way interaction between BDNF, 5-HTTLPR and cortisol but did not test this as the overall model fit was inferior as measured by Akaike's information criterion (AIC). The online tables (DS2-4) report the robustness of the final model to further adjustment/confounding by three variables: a grouping variable for those $(n=18)$ with subclinical depressive symptoms at study entry, and participant gender and age at entry.

We performed a post hoc power estimation for the logistic regression analysis using a bootstrap procedure. We repeated the procedure 1000 times and estimated the proportion of significant tests of the interaction terms. This approximates the power of our study taking the effect sizes to be their sample estimates. Results from traditional logistic regression are reported as unadjusted (univariate) and adjusted (multiple logistic regression) odds ratios with $95 \%$ confidence intervals. $P$-values for unadjusted estimates are reported using asymptotic values. Two analysts (T.C. and F.D.) independently replicated the general linear model analyses using both STATA version 10 and $R$ for Windows.

\section{Results}

The psychosocial and clinical characteristics of the sample are shown in Table 1. Depressive symptoms and morning cortisol levels were both significantly higher in females compared with males. At entry there were no differences in the proportion of anxiety disorders $\times$ gender but, compared with girls, boys had significantly more behaviour disorders.

\section{Gene variants and morning cortisol}

The distribution of the BDNF gene variant across the whole sample was: Val66Val $n=268(67 \%)$, Val66Met $n=109(27 \%)$, Met66Met $n=24(6 \%)$ and for 5-HTTLPR 1/l $n=155$ (39\%), 1/s $n=166(41 \%)$, s/s $n=80(20 \%)$. These two genes are somewhat associated in this sample (exact test, $P=0.052$ ) but as they are unlinked, this association may be a result of a selection effect in our cohort of at-risk adolescents, although this requires further confirmation. Mixed-effects linear regression showed no main effect of BDNF on morning salivary cortisol but the known main effect for 5-HTTLPR 's' allele on morning cortisol was retained ${ }^{20}$ (see online Table DS1). For morning salivary cortisol the within- and between-participant variance components were $60 \%$ and $40 \%$ respectively. The model was not improved by inclusion of two-way interactions so we did not test the interaction of BDNF and 5-HTTLPR on morning salivary cortisol.

\section{Predicting subsequent depressive episode onset}

The differences in factors at entry together with undesirable life events over the follow-up period between those who developed a new depressive episode and those who did not are documented in Table 2. At 12 months $175(48 \%)$ of the 365 reassessed participants reported one or more undesirable life events prior to onset of episode or month of interview in controls. Of these, $70(19 \%)$ reported a permanent loss, $94(26 \%)$ a personal disappointment, $17(5 \%)$ a personal danger, $41(11 \%)$ and $46(13 \%)$ a danger to a meaningful other (family member or

\begin{tabular}{|c|c|c|c|c|c|}
\hline & Females $(n=185)$ & Males $(n=216)$ & F & d.f. & $P$ \\
\hline Age, years: mean (s.d.) & $13.6(1.1)$ & $13.8(1.2)$ & 3.38 & 1,400 & 0.08 \\
\hline 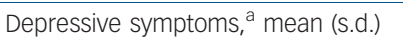 & $20.1(10.0)$ & $17.4(9.1)$ & 5.39 & 1,382 & 0.02 \\
\hline Morning cortisol, ng/ml: ${ }^{b}$ mean (s.d.) & $3.44(1.5)$ & $2.72(1.12)$ & 23.44 & 1,391 & $<0.0001$ \\
\hline Anxiety disorders, $n$ (\%) & $17(9)$ & $11(5)$ & & & $0.12^{\mathrm{C}}$ \\
\hline Behaviour disorders, $n(\%)$ & $3(2)$ & $15(7)$ & & & $0.99^{\mathrm{C}}$ \\
\hline BDNF & & & & & $0.99^{\mathrm{C}}$ \\
\hline Val66Val & $123(66)$ & $145(67)$ & & & \\
\hline Val66Met & $51(34)$ & $58(27)$ & & & \\
\hline Met66Met & $11(28)$ & $13(6)$ & & & \\
\hline 5-HTTLPR & & & & & $0.36^{\mathrm{C}}$ \\
\hline |/| & 72 (39) & $83(38)$ & & & \\
\hline $1 / \mathrm{s}$ & $71(61)$ & $95(44)$ & & & \\
\hline$s / \mathrm{s}$ & $42(38)$ & $38(18)$ & & & \\
\hline
\end{tabular}


Table 2 Factors at entry, subsequent life events and depression onset

\begin{tabular}{|c|c|c|c|c|c|}
\hline & \multicolumn{2}{|c|}{ Depressed episode during follow-up period } & \multicolumn{3}{|c|}{ Statistics } \\
\hline & No $(n=324)$ & Yes $(n=41)$ & $F$ & d.f. & $P$ \\
\hline \multicolumn{6}{|l|}{ Measures at entry } \\
\hline Depressive symptoms, mean (s.d.) & $17.6(9.0)$ & 26.5(9.9) & 33.9 & 1,358 & $<0.0001$ \\
\hline Morning salivary cortisol, mean (s.d.) & $3.0(1.3)$ & $3.8(1.6)$ & 11.13 & 1,364 & 0.0009 \\
\hline Age, years: mean (s.d.) & 13.6(1.2) & $13.6(1.1)$ & 0.00 & 1,364 & 0.96 \\
\hline Psychosocial risks, mean (s.d.) & $2.2(0.7)$ & $2.3(0.6)$ & & & $0.23^{\mathrm{a}}$ \\
\hline Gender, $n(\%)$ & & & & & $0.032^{\mathrm{a}}$ \\
\hline Females & $147(45)$ & $26(63)$ & & & \\
\hline Males & 177 (55) & $15(37)$ & & & \\
\hline$B D N F, n(\%)$ & & & & & $0.92^{\mathrm{a}}$ \\
\hline Val66Val & $214(66)$ & $27(66)$ & & & \\
\hline Val66Met & $90(28)$ & $11(27)$ & & & \\
\hline Met66Met & $20(6)$ & $3(7)$ & & & \\
\hline 5-HTTLPR, $n$ (\%) & & & & & $0.82^{\mathrm{a}}$ \\
\hline $\mathrm{I} / \mathrm{/} \mathrm{I}^{\prime}$ & 119 (37) & $17(41.5)$ & & & \\
\hline ' $1 / s^{\prime}$ & $140(43)$ & $17(41.5)$ & & & \\
\hline 's/s' & $65(20)$ & $7(17)$ & & & \\
\hline \multicolumn{6}{|l|}{ Measured at follow-up } \\
\hline Undesirable life events, $n$ (\%) & & & & & $<0.0001^{\mathrm{a}}$ \\
\hline None & 182(56) & $8(20)$ & & & \\
\hline One or more & $142(44)$ & $33(80)$ & & & \\
\hline
\end{tabular}

personal friend). Mental state reassessment showed that 41 (11\%) had experienced an episode of depression between entry and follow-up. There were no significant differences in the proportion of participants reporting undesirable life events or depression onset by BDNF or 5-HTTLPR genotype. Individuals were more likely to report a depressive episode if they were female, had self-reported higher depression scores at entry, had higher morning waking salivary cortisol at entry and reported experiencing one or more undesirable life events.

We analysed the risk of depression using multiple logistic regression with 357 (89\%) participants who had full data. For the purposes of analysis both gene variants are collapsed into two groups each as follows: BDNF as ValBDNF (Val66Val, $n=268(67 \%)$ ) and MetBDNF (Val66Met + Met66Met, $n=133$ (33\%)); 5 -HTTLPR as $1 / 1-5$-HTTLPR (1/l variant $n=155(39 \%))$ and $s-5-H T T L P R(1 / s+s / s$ variants $n=246(61 \%))$. The findings are shown in Table 3. There are significant effects for higher antecedent depressive symptoms, higher morning salivary cortisol and subsequent undesirable life events. The effect of higher morning salivary cortisol is qualified by the two two-way interactions with Val66Val variant of BDNF and the ' $\mathrm{s}$ ' variant of 5-HTTLPR genes respectively. The latter results implicate both gene variants moderating the risk of morning waking salivary cortisol on subsequent depression onset. There were no effects of age, gender or minor depression on these results (online Tables DS2-4). The power to detect significant associations at the $5 \%$ level was $61 \%$ for the interaction between BDNF and cortisol on risk of depression, and $44 \%$ for the interaction between 5-HTTLPR and cortisol. The power for main effects of BDNF and 5-HTTLPR was $64 \%$ and $57 \%$ respectively, although these were not our main interest. The probability of a new depressive episode occurring in the presence of morning waking cortisol by each gene is shown in Fig.1.

This shows line plots of the probability of subsequent depression for morning waking salivary cortisol $\times 5$-HTTLPR ( $1 / 1$ v. $1 / \mathrm{s}+\mathrm{s} / \mathrm{s}$ ) and BDNF (Val66Val v. any Met variant) respectively from the model in Table 3 . The figure shows the moderating effects of each gene variant on the risk that elevated

Table 3 Factors that predict onset of a new depressive episode over 1 year $^{\mathrm{a}}$

\begin{tabular}{|c|c|c|c|c|c|c|c|}
\hline \multirow[t]{2}{*}{ Factor } & \multicolumn{7}{|c|}{ No major depressive disorder $(n=317)$ v. major depressive disorder $(n=40)$} \\
\hline & Coefficient & s.e. & Odds ratio & $95 \% \mathrm{Cl}$ & Wald $\chi^{2}$ & d.f. & $P$ \\
\hline$B D N F$ & 2.828 & 1.23 & 16.9 & $1.5-188.4$ & 5.73 & 2 & 0.057 \\
\hline 5-HTTLPR & -3.004 & 1.29 & 0.1 & $1.6-252.6$ & 5.86 & 2 & 0.053 \\
\hline Depressive symptoms & 2.061 & 0.48 & 7.9 & $3.1-20.1$ & 18.17 & 1 & $<0.0001$ \\
\hline Morning cortisol & 1.519 & 0.85 & 4.6 & $0.9-24.2$ & 17.37 & 3 & $<0.001$ \\
\hline Life events & 1.265 & 0.47 & 3.5 & $1.4-8.9$ & 7.29 & 1 & $<0.001$ \\
\hline$B D N F \times$ morning cortisol & -2.337 & 0.98 & 0.1 & $0.14-0.67$ & 5.72 & 1 & 0.017 \\
\hline 5-HTTLPR $\times$ morning cortisol & 2.028 & 1.02 & 7.6 & $1.02-56.1$ & 3.96 & 1 & 0.046 \\
\hline Multiple degree of freedom test for interactions & & & & & 9.37 & 2 & 0.009 \\
\hline Overall model & & & & & 37.63 & 7 & $<0.0001$ \\
\hline \multicolumn{8}{|c|}{ 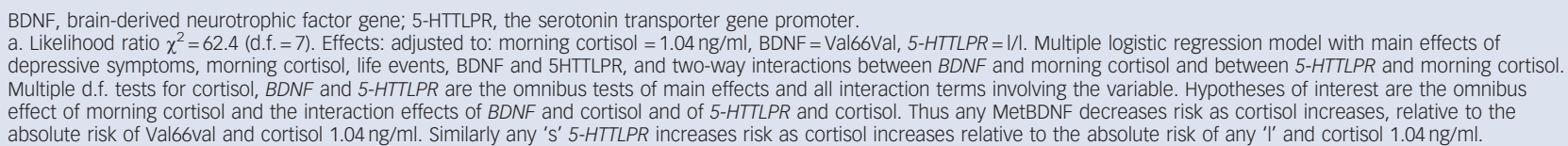 } \\
\hline
\end{tabular}



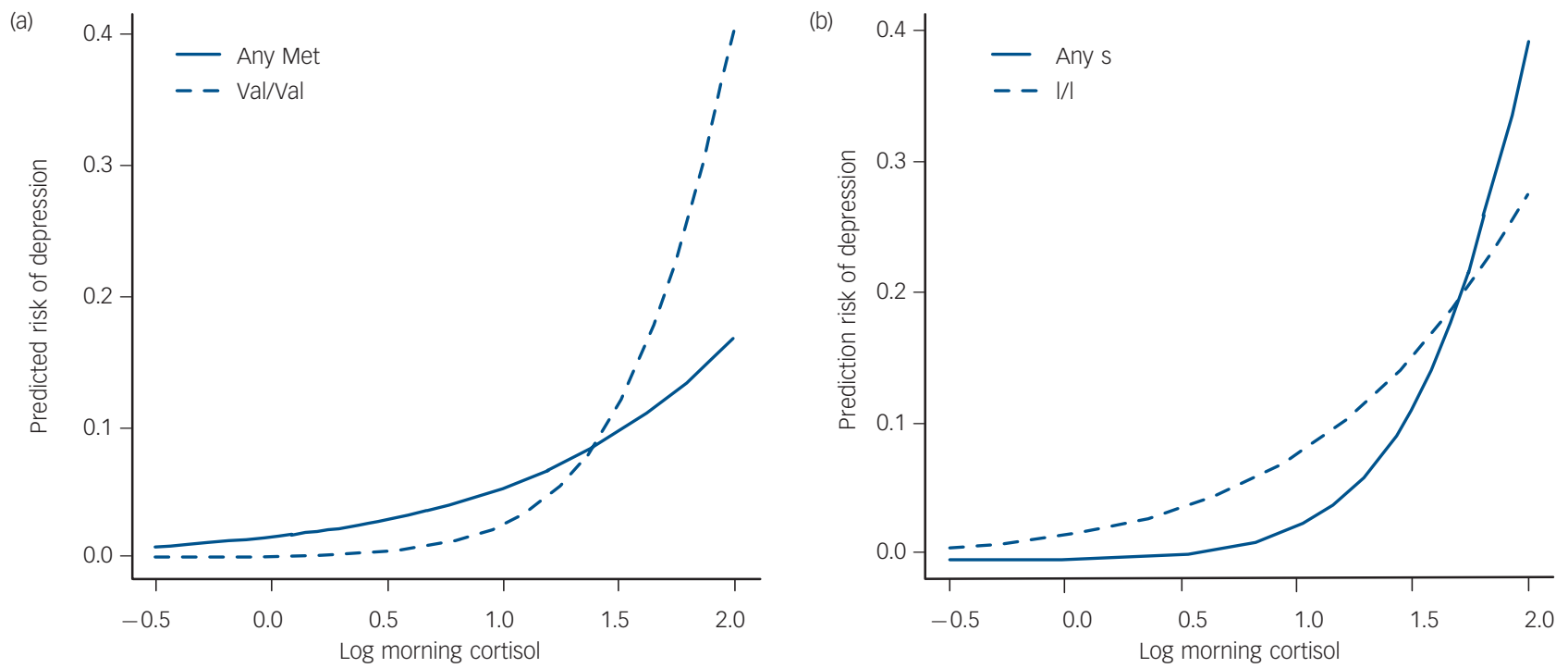

Fig. 1 Probability of subsequent major depression by either (a) BDNF (brain-derived neurotrophic factor gene) Val66Met or (b) 5-HTTLPR (the serotonin transporter gene promoter) and morning cortisol levels.

morning cortisol carries for the subsequent onset of a depression episode over the 12-month follow-up period. In each panel, the predicted risk from the logistic model described in the method above was calculated for each participant and the logittransformed risks then regressed back onto cortisol alone to give a smoothed marginal curve for our fitted model.

\section{Discussion}

We show for the first time that the onset of unipolar depression in adolescents can be predicted by a model including the moderating effects of two common gene variants within BDNF and the serotonin transporter on levels of morning salivary cortisol. In our risk sample each genetic variant had a significant two-way interaction with cortisol on the risk of depression.

\section{Genetic influences on vulnerability for depression onset}

Since more than $80 \%$ of depressive episodes arise in adolescents with prior psychosocial risks and elevated depressive symptoms, ${ }^{28}$ the current findings are likely to represent antecedent patterns of vulnerability for depression onsets and pathophysiological mechanisms underpinning psychosocial-risk processes in a considerable proportion of the adolescent population in general. The findings also show that the risk effects of genetically sensitive elevations in cortisol are not confounds of the depressive symptoms at entry or proximal undesirable life events during follow-up. The absence of gene $\times$ social environment interactions may be because this is a moderate-risk sample with no low-risk participants, a function of selecting undesirable events close to onset of disorder rather than cumulative indices of social adversities over time and/or not including those difficulties arising from earlier in the life course. ${ }^{29}$ Alternatively it may be because the mediating psychological processes such as individual differences in emotion processing and behavioural styles associated with event perception and occurrence have not been included in this study. ${ }^{30,31}$

\section{Possible influences of Val66Met BDNF on depression}

As noted elevated glucocorticoid levels reduce BDNF mRNA expression in the hippocampus ${ }^{8}$ and interfere with the ability of BDNF or serotonin-acting drugs to promote neurogenesis. ${ }^{9,10}$ We also noted a preliminary report suggesting that adults who carry the less common Met allele may be protected at the level of the brain from the deleterious effects associated with the short 's' allele of 5-HTTLPR. ${ }^{14}$ From the current results we speculate that when adolescent carriers of the common Val66Val BDNF variant are exposed to subsequent undesirable life events the risk for corticoid-mediated neurotoxicity may be increased because of the less protective nature of this BDNF gene variant in the face of stress. If true this would result in a cascade of cellular events inhibiting synaptic plasticity and neurogenesis and diminishing the liability for adaptive response behaviour. This speculative mechanism is hypothesis generating and awaits further study preferably with a sample size that can test for a three-way relationship between BDNF Val66Met, 's' allele 5-HTTLPR and morning cortisol.

\section{Implications of genetic influences on corticoid- mediated risk}

Overall the findings suggest that the two common genetic variants we studied are indexing functional interrelations between neurobiologically active systems and help to further specify morning waking salivary cortisol levels, a physiological endophenotype, as a biomarker for unipolar depressions emerging during adolescence.

\section{Limitations}

The modest sample size, data loss to follow-up and the power limitations in testing for moderator interactions limit any conclusions about causality for or specificity between our findings and affective disorder. Furthermore the selection of just two gene variants prevents a comprehensive interpretation of genetic effects on the social environment or the overall risk for subsequent affective disorders. Given the caveats surrounding the interpretation of gene-social environment interactions $s^{8,17,32}$ and 
the limitations represented by selection of single candidate gene variants in complex systems, ${ }^{33}$ these findings require replication in other populations to understand the impact of stratification due to gender, psychosocial and other risk factors.

\section{Further research}

A prospective developmental life-course cohort study with a larger sample would yield a greater proportion of conversions to depressive status of differing forms (sporadic, recurrent and chronic unipolar, bipolar I or II and rapid cycling types) over a longer time period and provide the necessary replication or refutation. Future studies also need to include measures of lifetime childhood difficulties and life-course histories of mental illness as there may be programming effects on individual differences in morning cortisol arising from the environment perhaps in genetically sensitive individuals. ${ }^{34}$ Measuring psychological processes may further characterise the mediating pathways between genes, cortisol and the social environment. For example, both 5-HTTLPR and BDNF gene variants may differentially influence reward processing and motivational incentives as well as response to negative mood ${ }^{15,35}$ but the relationships of these processes to morning cortisol levels and hence to subsequent depression remains unclear.

\footnotetext{
Ian M. Goodyer, MD, FRCPsych, FMedSci, Tim Croudace, PhD, Developmenta and Lifespan Research Group, Department of Psychiatry, University of Cambridge, Cambridge; Frank Dudbridge, PhD, Department of Epidemiology and Population Health, London School of Hygiene and Tropical Medicine, London; Maria Ban, PhD, Department of Clinical Neurosciences, University of Cambridge, Addenbrooke's Hospital, Cambridge; Joe Herbert, MB ChB PhD, Department of Physiology, Development and Neurosciences and the Cambridge Centre for Brain Repair, Cambridge, UK

Correspondence: Ian M. Goodyer, Developmental Psychiatry Section, Department of Psychiatry, University of Cambridge, Douglas House,

18b Trumpington Road, Cambridge CB2 8AH, UK. Email: ig104@cam.ac.uk

First received 18 Jan 2010, final revision 19 Mar 2010, accepted 25 Mar 2010
}

\section{Funding}

This work was funded by a Wellcome Trust programme grant (no. 053642) awarded to I.M.G. and J.H. T.J.C. is supported by a Career Scientist Award from the Department of Health. The work was carried out within the NIHR Collaborating Centre for Applied Health Research and Care hosted by the Cambridge and Peterborough Foundation Trust and the University of Cambridge.

\section{Acknowledgements}

We thank Helen Shires, Sarah Cleary and Jayne Wright for assays and DNA extraction. Genotyping was conducted in the Clinical Neurosciences Laboratory (M.B.).

\section{References}

1 Dunn V, Goodyer IM. Longitudinal investigation into childhood- and adolescence-onset depression: psychiatric outcome in early adulthood Br J Psychiatry 2006; 188: 216-22.

2 Fombonne E, Wostear G, Cooper V, Harrington R, Rutter M. The Maudsley long-term follow-up of child and adolescent depression. 1. Psychiatric outcomes in adulthood. Br J Psychiatry 2001; 179: 210-7.

3 Donnelly P. Progress and challenges in genome-wide association studies in humans. Nature 2008; 456: 728-31.

4 Hasler G, Drevets WC, Manji HK, Charney DS. Discovering endophenotypes for major depression. Neuropsychopharmacology 2004; 29: 1765-81.

5 Goodyer IM. Emanuel Miller Lecture: early onset depressions - meanings, mechanisms and processes. J Child Psychol Psychiatry 2008; 49 1239-56.
6 Mannie ZN, Harmer CJ, Cowen PJ. Increased waking salivary cortisol levels in young people at familial risk of depression. Am J Psychiatry 2007; 164 617-21.

7 Goodyer IM, Herbert J, Tamplin A, Altham PME. Recent life events, cortisol, dehydroepiandrosterone and the onset of major depression in high-risk adolescents. Br J Psychiatry 2000; 177: 499-504.

8 Kumamaru E, Numakawa T, Adachi N, Yagasaki $Y$, Izumi A, Niyaz M et al. Glucocorticoid prevents brain-derived neurotrophic factor-mediated maturation of synaptic function in developing hippocampal neurons through reduction in the activity of mitogen-activated protein kinase. Mol Endocrinol 2008; 22: 546-58

9 Huang GJ, Herbert J. Stimulation of neurogenesis in the hippocampus of the adult rat by fluoxetine requires rhythmic change in corticosterone. Biol Psychiatry 2006; 59: 619-24.

10 Pinnock SB, Herbert J. Brain-derived neurotropic factor and neurogenesis in the adult rat dentate gyrus: interactions with corticosterone. Eur $J$ Neurosci 2008; 27: 2493-500.

11 Egan MF, Kojima M, Callicott JH, Goldberg TE, Kolachana BS, Bertolino A et al. The BDNF val66met polymorphism affects activity-dependent secretion of BDNF and human memory and hippocampal function. Cell 2003; 112 257-69.

12 Verhagen $M$, van der Meij A, van Deurzen PA, Janzing JG, Arias-Vasquez A Buitelaar JK, et al. Meta-analysis of the BDNF Val66Met polymorphism in major depressive disorder: effects of gender and ethnicity. Mol Psychiatry 2010; 15: 260-71.

13 Strauss J, Barr CL, George CJ, King N, Shaikh S, Devlin B, et al. Association study of brain-derived neurotrophic factor in adults with a history of childhood onset mood disorder. Am J Med Genet B Neuropsychiatr Genet 2004: 131B: 16-9.

14 Pezawas L, Meyer-Lindenberg A, Goldman AL, Verchinski BA, Chen G, Kolachana BS, et al. Evidence of biologic epistasis between BDNF and SLC6A4 and implications for depression. Mol Psychiatry 2008; 13: 654 709-16.

15 Forbes EE. Where's the fun in that? Broadening the focus on reward function in depression. Biol Psychiatry 2009; 66: 199-200.

16 Martinowich K, Manji H, Lu B. New insights into BDNF function in depression and anxiety. Nat Neurosci 2007; 10: 1089-93.

17 Risch N, Herrell R, Lehner T, Liang KY, Eaves L, Hoh J, et al. Interaction between the serotonin transporter gene (5-HTTLPR), stressful life events and risk of depression: a meta-analysis. JAMA 2009; 301: 2462-71.

18 Monroe SM, Reid MW. Gene-environment interactions in depression research: genetic polymorphisms and life-stress polyprocedures. Psychol Sci 2008; 19: 947-56.

19 Uher R, McGuffin P. The moderation by the serotonin transporter gene of environmental adversity in the etiology of depression: 2009 update. $\mathrm{Mol}$ Psychiatry 2010; 15: 18-22.

20 Goodyer IM, Bacon A, Ban M, Croudace T, Herbert J. Serotonin transporte genotype, morning cortisol and subsequent depression in adolescents. Br J Psychiatry 2009; 195: 39-45.

21 American Psychiatric Association. Diagnostic and Statistical Manual of Mental Disorder (4th edn) (DSM-IV). APA, 1994.

22 Kaufman J, Birmaher B, Brent D, Rao U, Flynn C, Moreci P, et al. Schedule for Affective Disorders and Schizophrenia for School-Age Children - Present and Lifetime Version (K-SADS-PL): initial reliability and validity data. J Am Acad Child Adolesc Psychiatry 1997; 36: 980-8.

23 Shaffer D, Gould MS, Brasio J, Ambrosini P, Fisher P, Bird H, et al. A Children's Global Assessment Scale (CGAS). Arch Gen Psychiatry 1983; 40 1228-31.

24 Kent $L$, Vostanis $P$, Feehan $C$. Detection of major and minor depression in children and adolescents: evaluation of the Mood and Feelings Questionnaire. J Child Psychol Psychiatry 1997; 38: 565-73.

25 Daviss WB, Birmaher B, Melhem NA, Axelson DA, Michaels SM, Brent DA. Criterion validity of the Mood and Feelings Questionnaire for depressive episodes in clinic and non-clinic subjects. J Child Psychol Psychiatry 2006; 47: 927-34.

26 Harrell JEF. Regression Modelling Strategies: With Applications to Linear Models, Logistic Regression and Survival Analysis. Springer, 2005.

27 Adachi M, Barrot M, Autry AE, Theobald D, Monteggia LM. Selective loss of brain-derived neurotrophic factor in the dentate gyrus attenuates antidepressant efficacy. Biol Psychiatry 2008; 63: 642-9.

28 Jaffee SR, Moffitt TE, Caspi A, Fombonne E, Poulton R, Martin J. Differences in early childhood risk factors for juvenile-onset and adult-onset depression. Arch Gen Psychiatry 2002; 59: 215-22. 
29 Brown GW, Harris TO. Depression and the serotonin transporter 5-HTTLPR polymorphism: a review and a hypothesis concerning gene-environment interaction. J Affect Disord 2008; 111: 1-12.

30 Jacobs N, Kenis G, Peeters F, Derom C, Vlietinck R, Van Os J. Stress-related negative affectivity and genetically altered serotonin transporter function: evidence of synergism in shaping risk of depression. Arch Gen Psychiatry 2006; 63 989-96.

31 Canli T, Ferri J, Duman EA. Genetics of emotion regulation. Neuroscience 2009; 164: 43-54.

32 Munafo MR, Durrant C, Lewis G, Flint J. Gene X environment interactions at the serotonin transporter locus. Biol Psychiatry 2009; 65: 211-9.
33 Petryshen TL, Sabeti PC, Aldinger KA, Fry B, Fan JB, Schaffner SF, et al. Population genetic study of the brain-derived neurotrophic factor (BDNF) gene. Mol Psychiatry 2009; March 3 (Epub ahead of print).

34 Ouellet-Morin I, Boivin M, Dionne G, Lupien SJ, Arseneault L, Barr RG, et al Variations in heritability of cortisol reactivity to stress as a function of early familial adversity among 19-month-old twins. Arch Gen Psychiatry 2008; 65: 211-8.

35 Cools R, Roberts AC, Robbins TW. Serotoninergic regulation of emotional and behavioural control processes. Trends Cogn Sci 2008; 12: 31-40.

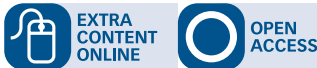

\section{psychiatry} in pictures

\section{Gaétan Gatian de Clérambault, 1872-1934}

\section{Vladimir Lerner, Eliezer Witztum}

Gaétan Henri Alfred Edouard Léon Marie Gatian de Clérambault was born at la Bourges, not far from Paris, on 2 July 1872. At his father's request, and in accordance with family tradition, he studied law, and only after graduation de Clérambault began to study medicine. His doctorate was dedicated to pilot health after aircraft accidents. From 1905 until his death in 1934, de Clérambault worked in different fields of medicine. His first psychiatric work, in 1909, was about hallucinations. De Clérambault introduced the term 'psychological (mental) automatism' and suggested that the mechanism of 'mental automatism' might be responsible for 'hallucination experiences'. He divided psychological (mental) automatism into three types: associative, sensitive and motor. This syndrome referring to delusions of external control is named Kandinsky-Clérambault's syndrome. In 1927 de Clérambault first described the syndrome 'psychose passionelle' - then named after him - in which a person believes that he or she is the focus of attention of some famous person. It is a type of paranoid delusion, with the content of an amorous quality. De Clérambault stated that the patient was usually a woman who had developed a delusional belief that a man, with whom she may have had little or virtually no contact, was in love with her.

De Clérambault was a well-educated, successful figure not only in medicine but also in art - many of his paintings are in museums now, as are his clothes models with oriental motifs. He took approximately 30000 photographs between 1914 and 1918. Some were taken as part of a research project on the symptoms of hysteria. He taught about the art of draped costumes at the Ecoles des Beaux Arts in Paris. Much of his photograph collection can be found at the Musée de l'Homme in Paris.

His encyclopaedic knowledge included five languages. On 16 November 1934, after two unsuccessful operations for cataracts, seated with his camera focused on the mirror in front of him, he shot himself with his officer's revolver. In 1942, one of his students, Jean Fretet, published two volumes of de Clérambault's works under the title Oeuvre Psychiatrique. De Clérambault's life and art are depicted in the film The Cry of Silk (1996) directed by Yvon Marciano.

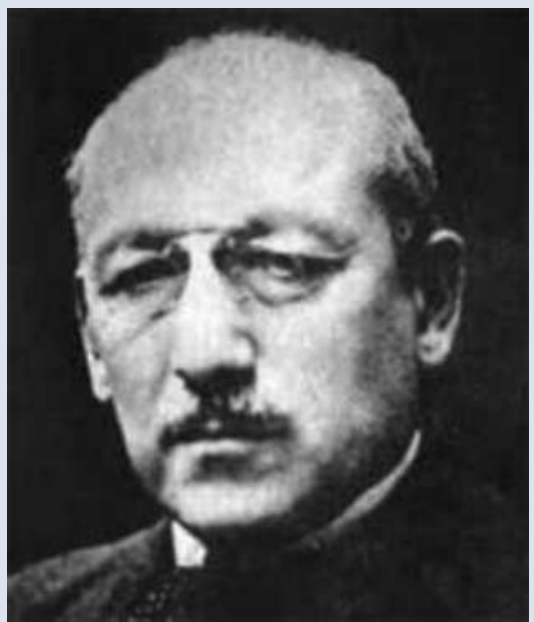

G. G. de Clérambault, 1880 (from the collection of Professor Lerner's father)

Vladimir Lerner, MD, PhD, Eliezer Witztum, MD, Ministry of Health Mental Health Center, Faculty of Health Sciences, Ben-Gurion University of the Negev, Be'er-Sheva, Israel 